\title{
EUTOMIA
}

Revista de Literatura e Linguística



\section{Instrumentos pedagógicos e sua relação com o desenvolvimento humano e a constituição profissional na docência}

\section{Pedagogical instruments and their relationship with human development and professional formation in teaching}

Resumo: Neste artigo socializamos discussões acerca do papel dos instrumentos pedagógicos na educação escolar e sua relação com o desenvolvimento humano e a formação de professores, quando serão problematizados indícios de alguns eventos que foram constituídos na memória de 17 licenciandos e 3 professores formadores em Ciências Biológicas, que possibilitam reconhecer suas compreensões sobre instrumentos pedagógicos decorrentes do percurso formativo vivenciado. A investigação foi desenvolvida na perspectiva da abordagem qualitativa de pesquisa em Educação e está caracterizada como um Estudo de Caso. Os dados foram construídos a partir de questionário e entrevistas semiestruturadas e organizados considerando os pressupostos teóricos da Análise Textual Discursiva (ATD). Para a interpretação dos resultados foram consultadas obras do referencial teórico da Psicologia Histórico-Cultural e de autores que discorrem sobre currículo, ensino, avaliação, aprendizagem e formação de professores. Os resultados indiciam que instrumentos pedagógicos utilizados em aulas se constituem/tornam eventos memorizados no percurso formativo, que orientam para a significação conceitual e para a produção de ideários de docência. É fundamental que o professor tenha compreensões sobre como o sujeito/aluno aprende e se constitui, atentando para a escolha, utilização e diversificação de instrumentos pedagógicos.

Palavras-chave: aprendizagem; avaliação; ensino; formação de professores.

Abstract: This article discusses the role of pedagogical instruments in school education and their relationship with human development and 
teacher training. It was carried an analysis of some events set in the memory of 17 pre-service teachers and 3 training teachers in Biological Sciences. It was possible to recognize their understandings on pedagogical instruments deriving from their formative experience. It was employed a qualitative research approach in Education, being characterized as a Case Study. Data were collected from a survey, semi-structured interviews and organized considering theoretical assumptions of Discursive Textual Analysis (DTA). Interpretation of results was based on Historical-Cultural Psychology and researchers of the fields: curriculum, teaching, evaluation, learning and teacher training. The results point out that pedagogical instruments employed in classes are constituted and became memorized events along teacher formation, what guide theoretical development and production of teaching ideas. It is necessary for teachers to develop knowledge about how the subject/student learns, paying attention to pedagogical instruments' choice, employment, and diversification.

Keywords: learning; assessment; teaching; teaching formation.

\section{Introdução}

O presente artigo tem como objetivo discutir sobre o papel dos instrumentos pedagógicos na educação escolar e sua relação com o desenvolvimento humano. Para tanto, analisaremos parte do percurso format ivo de um grupo de licenciandos e professores formadores de Ciências Biológicas, a fim de compreender implicações dos instrumentos pedagógicos para a significação de conhecimentos escolares no currículo. Temos como proposição inicial a ideia de que os instrumentos pedagógicos podem se estabelecer como elementos articuladores da aprendizagem, da constituição humana e da formação dos sujeitos professores.

Os resultados que estamos socializando são recorte de uma pesquisa de Mestrado Acadêmico na área de Educação, defendida e aprovada no ano de 2017. O estudo contou com a participação de licenciandos e professores formadores de um curso de Graduação em Ciências Biológicas - Licenciatura - de uma universidade federal situada no Estado do Rio Grande do Sul (RS), Brasil (BR). Por conseguinte, a sistemat ização deste artigo ${ }^{1}$ emanou de alguns debates e compreensões que foram produzidos durante o percurso da invest igação supracitada. No texto, a fim de preservar a identidade e manter o anonimato dos sujeitos envolvidos, os mesmos estarão nominados com nomes fictícios de inicial $L$ e $F$, respectivamente para se referir aos licenciandos e aos professores formadores.

\footnotetext{
${ }^{1}$ A pesquisa socializada neste artigo foi realizada com apoio da Coordenaç̧ão de Aperfeiçoamento de Pessoal de Nível Superior - Brasil (Capes) - Código de Financiamento oo1.
}

Eutomia, Recife, 27(1): 258-278, Out. 2020 
Neste trabalho partimos do pressuposto de que instrumentos pedagógicos podem ser entendidos como aqueles instrumentos dos quais o professor se apropria para o desenvolvimento da atividade ensino, como computadores, jogos, livros, apostilas, experimentos e provas (LEONTIEV, 1978; VIGOTSKI, 2001). Por serem portadores de signos, podemos afirmar que eles atuam como mediadores nos processos de ensino e de estudo e, sendo assim, possibilitam a aprendizagem. Signo, por sua vez, é a palavra portadora de um significado social que viabiliza o pensamento e a comunicação, promovendo a transformação do homem biológico em homem cultural (VIGOTSKI, 2001).

Vigotski e Luria (1996) argumentam que os signos e os instrumentos permitem ao sujeito memorizar conhecimentos do meio social e se desenvolver historicamente. Os autores explicam que, inicialmente, o homem utilizava signos e instrumentos para se comunicar com os outros e, a partir dessas interações, os signos e instrumentos foram ganhando novos significados e se transformando em elementos constitutivos do psiquismo. Isso nos leva a reflet ir sobre a teoria estudada e concebida por Vigotski (2001) de que o sujeito se converte em si mesmo ao estabelecer relações com os outros e com o ambiente.

Instrumentos e signos, para Silva (2013, p. 2), "são meios que orientam o comportamento humano de diferentes maneiras, permitindo ao indivíduo controlar e transformar o ambiente físico e social do qual ele é parte integrante, como também controlar e transformar seu próprio comportamento". Para esta autora, a atividade humana é produzida de forma mediada, posto que "instrumentos e signos são mediadores da atividade prática e da atividade psicológica do indivíduo humano, havendo uma ligação real entre eles tanto na história da evolução da espécie humana quanto no desenvolvimento de cada indivíduo" (Idem).

Considerando o contexto escolar, podemos afirmar que os signos manifestam o pensamento do professor e que os instrumentos viabilizam transmit ir conhecimentos aos alunos, facilitando a significação conceitual dos conteúdos abordados em sala de aula. Smolka (200ob, p. 30) explica que

se existe uma distinção crucial na orientação das atividades (instrumentos são dirigidos "para fora"; signos são dirigidos "para dentro"), queremos ressaltar que os instrumentos se caracterizam geralmente por sua finalidade e especificidade, enquanto os signos, na sua materialidade simbólica, são marcados por uma não especificidade (caráter difuso, 
contornos embaçados), pela impregnação (caráter seminal e "permeante") e pela reversibilidade (direcionados para o outro e para si).

As palavras, signos ou conceitos da exposição de um professor são essenciais e precisam ser introduzidos na atividade pedagógica. O uso de instrumentos pedagógicos precisa abranger a significação dos conceitos que ele proporciona. Nessa direção, "Leontiev afirma que, se quisermos construir na criança uma nova ação intelectual, é preciso antes exteriorizá-la, apresentá-la como uma ação exterior para, assim, acompanhar o movimento de sua transformação em uma ação interior" (MOURA; SFORNI; ARAÚJO, 2011, p. 45).

Para que a educação escolar contribua na formação e no desenvolvimento dos estudantes, o trabalho docente apresenta-se como um esteio. Compete ao professor definir como, quando e que conteúdos deverão ser problemat izados. Além disso, segundo Vigotski (2007), deve ser levado em conta que "cada assunto tratado na escola tem a sua própria relação específica com o curso de desenvolvimento da criança, relação essa que varia à medida que a criança vai de um estágio para outro" (p. 104). Nessa linha de pensamento, Moura et al. (2010, p. 261) advertem que:

\begin{abstract}
a atuação do professor é fundamental ao mediar a relação dos estudantes com o objeto do conhecimento, orientando e organizando o ensino. As ações do professor na organização do ensino devem criar, no estudante, a necessidade do conceito, fazendo coincidir os motivos da atividade com o objeto de estudo. O professor, como aquele que concretiza objetivos sociais objetivados no currículo escolar, organiza o ensino: define ações, elege instrumentos e avalia o processo de ensino e de aprendizagem.
\end{abstract}

Os instrumentos pedagógicos utilizados pelo professor no planejamento do seu ensino têm o potencial de facilitar a significação conceitual e também contribuir para a constituição humana de alunos e professores. Para tanto, precisam ser diversificados e inseridos nos espaços educativos de modo contextual, relacionando-se com a vida dos sujeitos, a fim de estabelecerem relações com os signos e mediar os processos interativos em sala de aula. Os conhecimentos científico-escolares precisam ser significados pelos alunos, e isso requer a realização da atividade de ensino por parte do professor e da at ividade de estudo por parte do aluno. Esses dois processos, segundo Leontiev (1978), são fundamentais para resultar na aprendizagem e promover constituição cultural. É imprescindível pensar que, "aprendizado não é desenvolvimento; entretanto, o aprendizado adequadamente organizado resulta em desenvolvimento mental" (VIGOTSKI, 2007, p. 103). 
A aprendizagem e o desenvolvimento humano requerem um processo de memorização voluntária, que acontece numa relação dialética às demais funções superiores, como a atenção voluntária, a linguagem superior e o pensamento por conceitos. Segundo a abordagem Histórico-Cultural, ao se apropriar de um conceito a linguagem faz com que o aluno consiga se referir a ele utilizando diferentes meios e expressões. O sujeito não produz memória voluntária das palavras, mas, sim, sobre seu sentido, além do que "detalhes de um conteúdo, já esquecidos, serão facilmente retomados dos livros, de artigos científicos, hoje, da Internet" (MALDANER, 2014, p. 39). Por isso, "o que os professores precisam entender é que as carências são de significações dos conhecimentos históricos e de como isso se realiza" (Idem).

Consoante Rocha (2013, p. 103), "a memória está implicada em todas as ações do ser humano e é essencial para a sua constituição histórico-cultural, já que sem memória não há história e não há cultura". O sujeito nada mais é do que o resultado daquilo que ele vivenciou, aprendeu e memorizou durante suas interações com o ambiente e a sociedade.

Partindo desses entendimentos, nessa discussão serão problematizados alguns eventos que foram constituídos na memória dos sujeitos inseridos nesta pesquisa licenciandos e professores formadores em Ciências Biológicas - que apresentam indícios sobre instrumentos pedagógicos experienciados em seu percurso histórico-cultural. $\mathrm{Na}$ escrita buscaremos sistematizar e "entender as condições, os modos de produção e as práticas que envolvem motivos e formas de lembrar e esquecer, maneiras de contar, de fazer e registrar histórias" (SMOLKA, 2000a, p. 168). Salientamos que os dados em análise foram construídos a part ir do desenvolvimento de questionário e entrevistas.

Compreendemos que a contextualização de instrumentos pedagógicos nos espaços educativos possibilita aos estudantes a apropriação de conhecimentos escolares, bem como a construção de ideários de docência. Braga (2000, p. 189) pressupõe que "já nascemos imersos em um processo de significação [...]. O que e como lembramos depende dos significados e sentidos que vão sendo historicamente produzidos nas interações, nas interlocuções". Para a mesma autora, "a recordação emerge em função dos interesses do presente e está ligada às at ividades prát icas da vida cot idiana" (2010, p. 160).

Sendo assim, depreendemos que não é por acaso que nós, na condição de professores, por vezes nos baseamos nas memórias advindas de nossa formação escolar e 
acadêmica para planejar e desenvolver nosso ofício profissional. Provavelmente o ensino que promovemos, por sua vez, também constituirá "marcas na memória dos alunos, que se embrenharão no curso de seu processo de escolarização e da vida" (ROCHA, 2013, p. 103). Isto posto, a pergunta que norteia este trabalho é: Que contribuições os instrumentos pedagógicos utilizados no ensino escolar podem oferecer para a aprendizagem e o desenvolvimento humano?

Por ora, reafirmamos a relevância de produzir entendimentos a respeito dos instrumentos pedagógicos que são utilizados pelos professores, bem como suas contribuições no que se refere à apropriação de conhecimentos culturais pelos alunos. Tais impressões também podem ser depreendidas de um excerto de entrevista, selecionado do nosso próprio contexto investigativo:

Livro, copiar do quadro infinitamente... as provas, por exemplo, decoreba direto! Prova de História, tu tinhas que decorar meia página pra responder uma questão e se faltava meia palavra tu ganhavas errado. Essa era a metodologia mais... era livro, prova e exercício [...] o professor sempre foi o centro. No meu processo ele sempre foi o centro no Ensino Básico (Franciele Entrevista).

A memória advinda da época de estudante, manifestada por Franciele, corrobora que o uso de alguns instrumentos pedagógicos, como o livro didát ico e a prova, são eventos memorizados pelos alunos durante o percurso histórico-cultural de escolarização, podendo também se constituir como fatores determinantes para o desenvolvimento humano nos espaços educativos. Do mesmo modo, o depoimento torna-se um sugestivo convite à discussão que aqui nos propomos a construir. Por conseguinte, apostamos que este estudo poderá trazer subsídios no que diz respeito a reflexões sobre alternativas viáveis para promover melhorias nos processos de ensino e de aprendizagem na Educação Básica e no percurso de qualificação profissional dos sujeitos professores.

\section{O contexto da pesquisa e os procedimentos metodológicos}

A sistemat ização do presente artigo se deu a part ir de uma pesquisa de Mestrado em Educação nas Ciências, que discutiu sobre a relação do trabalho educativo com o desenvolvimento da memória humana e a formação de professores. A temática "instrumentos pedagógicos e sua relação com o desenvolvimento humano e a constituição 
profissional na docência" é uma discussão emergente nos resultados da dissertação defendida (WYZYKOWSKI, 2017).

O percurso investigativo foi desenvolvido na perspectiva da abordagem qualitat iva de pesquisa em Educação (LUDKE; ANDRÉ, 1986) e está caracterizado como um Estudo de Caso. Apoiadas em Yin (2001), destacamos o Estudo de Caso é uma metodologia que propicia compreender "fenômenos individuais, organizacionais, sociais e políticos" e "preservar as características holísticas e significativas dos eventos da vida real - tais como ciclos de vida individuais" (YIN, 2001 p. 21).

A pesquisa foi realizada junto a Universidade Federal da Fronteira Sul, Campus Cerro Largo, no Rio Grande do Sul (RS). Part iciparam 17 licenciandos do curso de Graduação em Ciências Biológicas - Licenciatura -, matriculados no componente curricular Estágio Supervisionado IV: Biologia do Ensino Médio, durante o segundo semestre do ano de 2015 . O estudo também envolveu a participação de três professores formadores, responsáveis pelo desenvolvimento do referido componente curricular.

A invest igação foi aprovada pelo Comitê de Ética em Pesquisa da Instituição à qual as autoras estão vinculadas. O Termo de Consentimento Livre e Esclarecido (TCLE) foi disponibilizado e assinado pelos participantes no momento da apresentação do projeto nas dependências da inst ituição envolvida antes de iniciar as at ividades inerentes ao estudo em questão.

Como já mencionamos, para preservar a identidade e manter o anonimato dos sujeitos envolvidos designamos os licenciandos com nomes fictícios de inicial $L$ e aos professores formadores atribuímos nomes de inicial F. Para a construção dos dados na pesquisa, que serão reportados na tessitura deste texto, foram desenvolvidos questionário com os licenciandos e entrevistas semiestruturadas com os professores formadores e licenciandos. Foi pert inente utilizar dois instrumentos de produção de dados. As entrevistas possibilitaram complementar ou melhor explicitar algumas informações que os licenciandos registraram inicialmente no questionário.

O quest ionário e as entrevistas foram realizados na universidade em data e horário previamente agendados. Eles cont inham perguntas que pretendiam delimitar o perfil dos sujeitos de pesquisa e sistematizar, de um modo direto e objetivo, o posicionamento dos sujeitos, especialmente ante a alguns aspectos do processo educativo que ficaram 
memorizados, e que estão relacionados ao ensino, à aprendizagem, ao currículo, à imagem do ser professor e à constituição da docência em Ciências Biológicas. As entrevistas foram gravadas em áudio e, posteriormente, transcritas. Destacamos que foi pertinente utilizar entrevistas semiestruturadas para a produção de dados, pois possibilitaram compreender alguns "aspectos afetivos e valorativos dos informantes que determinam significados pessoais de suas at itudes e comportamentos" (BONI; QUARESMA, 2005, p. 75).

O material produzido a part ir das interações estabelecidas, por meio de entrevistas e questionários, foi organizado considerando os pressupostos teóricos da Análise Textual Discursiva (ATD). Segundo Moraes e Galiazzi (2011), o dinamismo da ATD possibilita tanto a análise de conteúdos quanto a análise do discurso em estudos qualitativos, e compreende a realização das etapas de unitarização, categorização e captação do novo emergente.

Partindo dessas compreensões, inicialmente realizamos, na primeira etapa, uma desmontagem de textos nos questionários e entrevistas, e formamos nosso corpus textual de análise. Observamos todos os dados produzidos e selecionamos excertos que cont inham significados referentes ao tema de pesquisa. Os excertos marcados se constituíram em nossas unidades de análise (MORAES, 2003).

Em seguida, na segunda etapa, conforme indica Moraes (2003), reportamos ao referencial teórico que norteia a investigação e estabelecemos relações entre as unidades de análise. Com isso, manifestou-se como categoria emergente "instrumentos pedagógicos", identificada a partir de determinadas expressões manifestadas pelos sujeitos part icipantes.

Por fim, desenvolvemos a etapa que o autor nomeia de captação do novo emergente a partir da análise de unidades selecionadas, que resultou na produção do metatexto apresentado neste artigo. Para tal construção, recorremos ao corpus textual da pesquisa relacionando-o com pressupostos teóricos da literatura. Nesse processo, organizamos nossas ideias, argumentando e referenciando proposições, e assumimos a autoria de um conhecimento que foi sendo sistematizado na escrita que, por ora, aqui apresentamos (MORAES, 2003).

Para a interpretação do corpus textual e sistematização de compreensões sobre o tema em discussão, consultamos obras do referencial teórico da Psicologia HistóricoCultural, como Vigotski (2001), Leontiev (1978) e Luria (1999), dentre outros que tratam do 
desenvolvimento do ser humano. Também estudamos autores que discorrem sobre currículo, ensino, avaliação, aprendizagem e formação de professores (GERALDI, 1994; LAPLANE, 1997; CARVALHO; GIL-PÉREZ, 2011; MALDANER, 2014).

Desta forma, pelo dinamismo da ATD, apropriando-nos de sentidos imbricados no material empírico, com o apoio das concepções teóricas de diversos autores, construímos alguns resultados concomitantes com o objetivo inicialmente expresso na introdução do artigo. A seguir, compartilharemos algumas aprendizagens que desenvolvemos, ponderando, de modo geral, discussões sobre instrumentos pedagógicos. Ressaltamos que as expressões dos sujeitos de pesquisa a serem problematizadas durante a discussão, advindas dos questionários e entrevistas realizadas, estão demarcadas no texto com grifos em itálico.

\section{Discussão dos Resultados}

Os resultados indiciam que o uso de instrumentos pedagógicos durante o percurso de escolarização foi um evento memorizado pelos licenciandos e professores formadores envolvidos nesta pesquisa. No questionário, Luana e Luiza, respectivamente, descrevem a memória de que "fizemos um terrário em sala de aula e observamos por dias" e que "na 6a série tínhamos um aquário com girinos na sala" (Luana - Questionário; Luiza Quest ionário). Na mesma direção, Larissa tem a memória da "part icipação em seminários e feiras de ciências" (Larissa - Questionário) e Lavínia expressa: "lembro de aulas práticas de biologia, caminhadas na praça para reconhecer e diferenciar gimnosperma e angiosperma, aulas de laboratório. Lembro perfeitamente de páginas de livros que utilizei, exercícios e trabalhos que fiz" (Lavínia - Questionário).

Em nossa análise, evidenciamos que o livro didático foi um instrumento pedagógico recorrentemente destacado pelos sujeitos participantes desta pesquisa, quando expressaram no questionário e/ou entrevista algumas memórias constituídas no seu percurso formativo. Em algumas situações vivenciadas no período de escolarização, conforme depoimentos de licenciandos e formadores, o livro didát ico foi o próprio currículo em ação, pois guiava o trabalho docente e seu conteúdo parecia ser idealizado como verdade inquestionável (GERALDI, 1994). Lourdes revela: "minhas aulas eram baseadas no 
livro didático, sem muitas aulas práticas. [...] desenvolvíamos projetos interdisciplinares, mas no geral eram baseados no livro didático" (Lourdes - Questionário).

Segundo Güllich (2013), em parte das escolas brasileiras o livro didático é o principal, senão o único, instrumento pedagógico disponibilizado aos alunos e professores. O autor indica, porém, que é fundamental ter consciência sobre os limites e potencialidades que estão imersas em seu enredo. O que preocupa é que, algumas vezes, em razão de problemas de formação e da falta de conhecimento sobre como fazer uso apropriado desse instrumento pedagógico para o ensino e a aprendizagem, os professores podem transmit ir aos seus alunos erros conceituais e concepções epistemológicas simplificadas ou equivocadas, que podem estar presentes no enredo desse material.

Semelhante ao relato de Lurdes, Larissa também recorda que experienciou um ensino tradicional em decorrência da frequente utilização do livro didático. Durante a entrevista, Larissa evocou a memória:

A professora sentava lá na frente e ela dizia assim "façam um resumo de tal página até tal página... escrevam no caderno... façam um resumo e depois tem um mapa pra vocês pintarem". Essa era a aula dela. E eu percebo isso, eu não aprendi muito com isso. Eu realmente não... não aprendi! [...] Eu acho que somente fazer resumo... o aluno tá copiando do livro! Tipo, nós fazia resumo: pulava umas linhas, copiava outras linhas... nem sabia o que tava escrevendo, né?! (Larissa - Entrevista).

A manifestação de Larissa exemplifica situações que ela vivenciou na condição de estudante, em que "o livro didático adota o professor e não o inverso", e também indicia que isso possa ter acontecido em decorrência da "maquinaria didática que o constitui e o extrapola, incorporando-se ao 'saber fazer' do professor, independente da presença física do livro didático" (GERALDI, 1994, p. 119).

Conforme repreende Larissa, contudo, o processo de aprender não se reduz à tarefa de reproduzir os conceitos tal e qual são emitidos em sala de aula ou escritos nos compêndios didáticos. Sendo assim, o discurso de Larissa convida a reflet ir que a prática do professor não pode se limitar ao discurso impregnado no livro didático, tampouco ignorar a possibilidade de ensinar a partir de outros instrumentos pedagógicos. Para que ocorra a aprendizagem é de suma importância que o professor realize a atividade de ensino e oriente o aluno para a atividade de estudo. Para tanto, deve levar em conta algumas características que compõem esses processos, como a "organização e sistematização 
lógica, a promoção de estabelecimento de relações e conexões internas entre os objetos e fenômenos percebidos, mediando a percepção por conceitos lógicos, abstratos e, sobretudo, pelo domínio de significados a ele vinculados" (MARTINS, 2013, p. 302).

No entendimento de Güllich (2013, p. 39), não é necessário condenar ou banir o uso do livro didático, mas interpretá-lo "como uma possibilidade e não como a única via de produção da aula". Desta maneira, nas aulas com o livro didático é importante que o professor observe como são apresentados os conceitos ou definições, também vale atentar se os conteúdos estabelecem relações com a sua historicidade e o cot idiano dos alunos, de modo que favoreçam uma problematização sobre o que é Ciência. Junto disto, a part ir dos instrumentos pedagógicos o professor pode intermediar reflexões e entendimentos a respeito de visões estereotipadas dos cientistas, por vezes presentes no contexto escolar, promovendo compreensões sobre como se desenvolve a produção científica e sua importância para a cultura e a sociedade.

Os instrumentos pedagógicos têm o potencial de articular a apropriação de conhecimentos escolares, contribuir para a constituição humana e também influenciar a formação dos sujeitos professores. Contudo, eles por si só não melhoram a qualidade de ensino e não promovem aprendizagens nas aulas. Ao fazer uso de um instrumento pedagógico é imprescindível pensar na relação a ser estabelecida com os conceitos científico-escolares.

Sendo assim, na atividade de ensino o professor precisa pensar nos conceitos específicos da disciplina que leciona e, na condição de docente desta disciplina, elencar quais são os instrumentos pedagógicos mais viáveis para a problematização e o entendimento dos conteúdos. Além do domínio de conhecimentos didáticos e específicos da sua área de formação profissional, o professor também necessita da apropriação de conhecimentos sobre os modos de construção histórica e cultural dos conceitos e dos instrumentos pedagógicos. Isto é fundamental para subsidiar possíveis intermediações que venham a se desenvolver junto aos alunos durante as aulas, em meio ao movimento de discussões e interações sobre os conteúdos estudados.

Conforme Neuville (2011, p. 92), "os sujeitos envolvem-se em uma atividade porque Ihe atribuem valor". Na escola, os alunos devem aprender e precisam de motivos que o levem a estudar, e isso é influenciado pelos instrumentos pedagógicos usados nas 
atividades propostas em sala de aula. Vale considerar que aulas consecutivamente mediadas a part ir dos mesmos instrumentos pedagógicos podem dispersar a atenção dos alunos e interferir na aprendizagem. Ademais, quando o aluno faz uma atividade do seu interesse, aumentam as possibilidades de estabelecer significados aos conceitos abordados.

Para Eccheli (2008), o professor "precisa ser capaz de perceber as dificuldades e necessidades dos alunos, além de constantemente reflet ir sobre a sua prática pedagógica e planejar atividades desafiadoras e motivadoras" (p. 211). Isso, contudo, não se configura como uma tarefa fácil, considerando que nem sempre o professor tem uma formação direcionada para esse fim. A manifestação de Flávia parece ilustrar esse desafio: "ela [professora] pedia pra gente trazer os materiais, alguns materiais, mas aí... numa forma bem tradicional, não é? [...] E como é marcante isso; que o professor... a gente não dá o que a gente não tem! não é? (Flávia - Entrevista).

Mesmo com tantas dificuldades imersas na profissão, o professor carece produzir constantemente uma reflexão crítica à própria prática e formação. Isso inclui estar atento à escolha e à diversificação dos instrumentos pedagógicos que vão atuar junto aos signos para mediar a significação conceitual em sala de aula. O professor precisa ensinar os alunos e oferecer condições para que todos aprendam; isso inclui considerar que eles não aprendem da mesma maneira, tampouco no mesmo tempo. Os instrumentos pedagógicos, além de potencializar a aprendizagem e a significação conceitual, também podem orientar para a produção de modelos de ensino, métodos de avaliação e para a produção de ideários de docência.

Cabe ainda ressaltar que a diversificação de instrumentos pedagógicos no ensino pode não atuar junto aos motivos dos alunos para desenvolver a atividade de estudo (LEONTIEV, 1978). Para desenvolver a significação de conhecimentos, a atividade de estudo do aluno é tão importante quanto a atividade de ensino do professor. Somente a diversificação de instrumentos pedagógicos na atividade de ensino, mesmo tornando as aulas mais atrat ivas, não garante a apropriação conceitual. É necessário est imular o aluno a desenvolver a atividade de estudo. Schroeder e Tomio (2020, p. 3) esclarecem que

pela atividade de estudo, nos processos de apropriação do conhecimento, há o desenvolvimento de novas formações, ou seja, o desenvolvimento de um produto mental novo - uma nova forma de pensar. Isto denota uma importante característica da atividade: a natureza investigativa, que 
conduz a um protagonismo ativo e criativo pelos estudantes, uma vez que são desafiados a percorrer a trajetória investigativa feita por aqueles que desenvolveram determinado conceito teórico. O estudo a que nos referimos, com caráter produtivo e não reprodutivo, trata-se daquele que conduz o estudante a engajar-se em at ividades para sua evolução como ser social.

Conne (1996, p. 238) é assert ivo ao explicar que "compete ao professor aproveitar judiciosamente a interação cognitiva que consegue manter com os seus alunos e a situação que ela lhe propõe, a fim de ativar o desenvolvimento dos seus conhecimentos". O ensino em sala de aula deve atender a todos, pois "o que um sujeito social deixa de fazer, por não ter sido incluído na cultura de seu tempo, fará falta para todos e/ou diminui a qualidade de vida de todos, conforme defende Bakhtin" (MALDANER, 2014, p. 18). Diversificar os instrumentos pedagógicos e utilizá-los de um modo contextual parece ser uma ação concreta, com condições de ampliar as possibilidades de aprendizagem nos contextos escolares e potencializar o desenvolvimento dos estudantes.

Os resultados deste estudo deixam eminente que aulas diferenciadas, conduzidas a partir da utilização de distintos instrumentos pedagógicos, são memorizadas pelos estudantes como eventos positivos de seu percurso de escolarização. No questionário, Lúcia atribui importância às "at ividades práticas com escritas de relatório e saídas a campo" (Lúcia - Questionário) e Laís sublinha que "a partir da pesquisa o aluno formula suas concepções, aprende [...] e não esquece" (Laís - Questionário). Nas entrevistas é compreensível que no ensino de Ciências "tem que ter aula prática, com certeza, não é?... aula experimental... tem leitura, tem muita pesquisa em sala de aula, não mediada pelo livro didático" (Laís - Entrevista).

Manifestações como estas revelam que, além do livro didático, o ensino de Ciências e Biologia abrange uma área do conhecimento que possibilita a abordagem dos conteúdos a partir de diferentes instrumentos pedagógicos, tais como filmes, jogos didáticos, trilhas ecológicas, práticas experimentais, entre outras. Compreendemos que a diversidade de instrumentos pedagógicos motiva os alunos à participação nas aulas. Para tanto, o professor precisa "saber apresentar adequadamente as atividades a serem realizadas, para tornar possível que os alunos adquiram uma concepção global da tarefa e um interesse pela mesma" (CARVALHO; GIL-PÉREZ, 2011, p. 54). 
É fundamental entender, contudo, que a atividade social do professor deve ser um processo intencional. Ao optar por determinado instrumento pedagógico em sala de aula, ele necessita ter se apropriado dos significados que estão nele imbricados para fazer seu uso contextualizado junto aos alunos. Tem de haver compreensão de que os instrumentos pedagógicos estão constituídos de conhecimentos produzidos pelo homem ao longo da História da humanidade; não é por acaso que eles existem e podem mediar a aprendizagem, favorecendo a constituição humana.

Ademais, tão importante quanto pensar nos instrumentos de ensino é pensar nos instrumentos utilizados para promover a avaliação dos alunos, a fim de tentar perceber potencialidades e fragilidades na aprendizagem.

Segundo Melo e Bastos (2012, p. 202), "a avaliação é uma questão que merece a reflexão dos professores, que devem se questionar sobre os instrumentos utilizados, sua produção, a frequência em que ocorrem, os critérios de avaliação e os seus objet ivos". Se o ensino e a avaliação são desenvolvidos de modo linear, sem a preocupação quanto às prováveis limitações no uso recorrente de determinados instrumentos pedagógicos, o aluno não aprende e não se desenvolve culturalmente.

Ao refletir sobre o processo educativo vivenciado na Educação Básica e no Ensino Superior, Luiza consegue trazer à memória "aulas muito tradicionais, slides com muito texto onde só o professor fala do início ao fim, fazendo com que a aula se torne muito cansativa, sem contar que nestas aulas só é apresentado conteúdo, não, nenhuma atividade sobre, a não ser na prova" (Luiza - Questionário). Estas expressões vão ao encontro da manifestação de Laís, pois contribui para "o ato de decorar o conteúdo para a avaliação e, após isto, ele se torna um aprendizado defeituoso que logo é esquecido" (Laís, 2015 - Questionário). As declarações de Luiza e Laís convidam a reflet ir a respeito do tempo necessário para a memorização e a significação dos conceitos científico-escolares.

O ensino deve dar condições para que os alunos se apropriem de conhecimentos do meio cultural. Esses conhecimentos, por sua vez, precisam ser constituídos na memória voluntária de longo prazo de cada sujeito. A literatura explica que nem tudo o que vivenciamos no contexto social conseguimos desenvolver na memória de longo prazo, pois é realizada uma seleção de experiências que serão conservadas. Por isso, segundo Luria (1999), o sujeito memoriza aquilo que tiver algum significado e o processo é facilitado 
quando as informações possuem uma organização semântica, ou pela via da atividade realizada pelo sujeito ou, ainda, quando se estabelecem relações entre as informações e as peculiaridades individuais durante a formação da memória.

Luria (1999), que é um autor da abordagem histórico-cultural e que também discute sobre aspectos neurofisiológicos envolvidos na const ituição da memória humana, enuncia que a formação das memórias de longo prazo é um processo que pode demorar várias horas, pois as informações passam por uma série de eventos antes de serem significadas e conservadas. Isso traz a necessidade de reflet ir sobre o período de tempo que é dest inado para problemat izar cada conceito em sala de aula.

Seria um equívoco esperar que vários conceitos trabalhados em um curto período de tempo sejam entendidos pelos alunos. De acordo com a teoria defendida por Leontiev (1978), o estudo é a atividade principal do aluno. Tão importante quanto isso, porém, é o fato de o aluno precisar de tempo para pensar e interagir sobre a matéria no ambiente escolar junto aos demais autores/atores que participam do currículo.

Vigotski (2001) ensina que a const ituição humana somente é possível a partir de processos interativos que se estabelecem nos meios sociais, como na escola. Ao contrário do que, às vezes, possa parecer, quando o professor expõe os conteúdos e os alunos ficam em silêncio não significa, necessariamente, que eles estão aprendendo, tampouco desenvolvendo suas capacidades cognitivas (LAPLANE, 1997). Nesse ínterim, durante a entrevista, Fernando destacou que "o bom professor consegue antecipar inclusive perguntas. Ele vai respondendo questões possíveis que, pela experiência dele, já sabe que estão... estão no diálogo, muitas vezes no silêncio de alguns alunos, mas são necessárias de serem respondidas" (Fernando - Entrevista).

Os depoimentos de Luiza, Laís e Fernando também levam a pensar que nem sempre a avaliação é utilizada de modo que seja capaz de contribuir com o desenvolvimento do aluno. Isso, todavia, não é proposital; por vezes o professor não tem consciência da existência de tal limitação em sua prática. Nos casos descritos pelas duas licenciandas, respectivamente, mesmo não sendo intencional, parece que a avaliação visava a identificar se o aluno realizou uma memorização mecânica do conteúdo e não, essencialmente, se houve a devida apropriação dos significados envolvidos. Nessa direção, Vieira e Sforni (2010) alegam que 
dos ensinamentos de Vigotski é possível inferir que, se o conceito não é algo isolado e só existe em relação com outros conceitos, ele não pode ser avaliado fora do sistema do qual faz parte. Isso significa que é necessário verificar a apropriação de conceitos estabelecendo-se relações com outros conceitos. Dessa maneira, não basta definir algo, descrever suas características e funções, pois a definição ou a descrição verbal ou escrita não implicam apropriação. Se as avaliações, mesmo que de diferentes formas, mantiverem-se presas à designação verbal do conceito, sem o estabelecimento de suas ralações com outros conceitos, e se essa generalização não descer ao concreto, sejam essas formas tradicionais ou inovadoras, não conseguem avaliar de fato se houve a apropriação conceitual (p. 53).

Partindo desta inferência, é possível interpretar que, no decorrer do percurso escolar formativo, os licenciandos inseridos neste estudo vivenciaram processos avaliativos tradicionais, como também fica nít ido na fala de Leandro: "sei lá... aquela pressão por nota! Tudo movido a notas e tudo movido a ... métodos avaliativos que pressionam a gente a tentar o desempenho e se tu não tens desempenho tu não se enquadras naquela perspectiva que eles precisam" (Leandro - Entrevista). Discursos como esse reforçam a pertinência de considerar, na perspectiva de Vigotski (2001), que os instrumentos pedagógicos e os signos são responsáveis pela mediação nos processos de ensino e de aprendizagem em sala de aula. O professor é o intermediador no contexto educativo e precisa contextualizar sua prática, com instrumentos pedagógicos de ensino e de avaliação apropriados, a fim de ocorrer a aprendizagem e a memorização voluntária dos conteúdos.

Igualmente, avaliar não é uma simples atribuição de nota ao aluno, mas também um modo de o estimular à atividade de estudo, bem como depreender indícios de que houve apropriação de conhecimentos escolares. Vieira e Sforni (2010, p. 55) entendem que "verificar se o aluno está desenvolvendo ou desenvolveu a capacidade de utilizar o conceito como instrumento do pensamento deve ser objeto da atenção dos professores no momento da elaboração e acompanhamento da avaliação".

Na concepção de Schroeder e Tomio (2020, p. 16) "professores engajados podem inspirar expectat ivas para o desenvolvimento de uma compreensão não determinista sobre como construímos a nossa humanidade e nossos códigos e como a ciência é fundamental para esta compreensão". Seguindo a linha de pensamento, Vieira e Sforni (2010, p. 55) afirmam que "aprender um conceito não é apenas saber o seu conteúdo, mas também saber fazer uso dele como instrumento para pensar os objetos e fenômenos". 
Cabe sinalizar que em situações específicas, nem sempre o professor realiza uma atividade de ensino que ajudaria o aluno a desenvolver suas capacidades cognitivas. Com apoio em Leont iev (1978) e Vigotski (2001), nos referimos àquela atividade do professor que se estrutura de modo a permitir que os sujeitos interajam, mediados por um conteúdo, negociando significados.

Os instrumentos pedagógicos, escolhidos e usados pelo professor na atividade de ensino para mediar a aprendizagem em suas aulas, viabilizam motivos para que os alunos desenvolvam a at ividade de estudo. Compreendemos, todavia, que é preciso considerar que os alunos são diferentes e, por isso, se apropriam dos conhecimentos culturais de modos distintos. Assim, é necessário diversificar os instrumentos pedagógicos em sala de aula a fim de tentar envolver os alunos em um diálogo interativo, respeitando as particularidades individuais que estão inseridas em um determinado grupo. Tanto quanto o cuidado necessário em relação ao uso e à diversificação de instrumentos pedagógicos de ensino, também é preciso direcionar uma reflexão no processo de avaliação das aprendizagens dos alunos, atentando para a escolha de instrumentos avaliativos condizentes com o percurso curricular. Melo e Bastos (2012) discorrem que

não existe fórmula pronta para que o professor realize uma boa avaliação. Os instrumentos devem ser diversificados, sucessivos, participativos, relevantes e significativos, sendo construídos pelo professor de modo que se possa compreender como a construção do conhecimento está ocorrendo em seus alunos. Diversificando os instrumentos é possivel abranger todos os aspectos do desempenho do aluno. Sugerimos considerar e valorizar a participação do aluno, seus exercícios feitos em aula e em casa, trabalhos de pesquisa em grupo e individual, interpretação, produção textual, debates, organização do caderno, frequência, disciplina, seu interesse, iniciativa, autonomia, questionamentos, empenho e desempenho. Essas observações devem fazer parte do dia a dia do professor, pois trata-se de considerações que não são possiveis de serem avaliadas com uma prova. É importante a utilização de vários instrumentos, no sentido de avaliar o aluno em todas as suas vertentes ( $p$. 201).

Essas ideias ajudam a compreender que os processos de ensino e de avaliação devem ser interpretados como oportunidade de aprendizagem tanto para o aluno quanto para o professor, e não como um momento de acerto de contas entre esses autores/atores do contexto educativo. Na concepção do professor Fernando, os alunos "precisam aprender e, se eles não aprendem, é porque, também, eu não ensino" (Fernando - Entrevista). Isto reforça a relevância de praticar uma reflexão sobre e para a escolha, utilização e 
diversificação dos instrumentos pedagógicos de ensino e de avaliação, para aumentar as possibilidades de aprendizagem e desenvolvimento cultural de alunos e professores.

\section{Algumas Considerações}

Os resultados construídos indiciam que instrumentos pedagógicos utilizados por alunos e professores acabam se constituindo em eventos memorizados no percurso formativo. Os sujeitos envolvidos na investigação atribuíram sentidos para algumas memórias advindas do processo de constituição. Os licenciandos e os professores formadores destacaram, em seus depoimentos, que vivenciaram uma formação nos moldes tradicionais que nem sempre resultava na aprendizagem de conteúdos escolares, na qual o livro didático foi o orientador da atividade de ensino e a avaliação não era realizada de um modo contextual. Os dados permitem afirmar que as memórias de instrumentos pedagógicos de ensino e de avaliação contribuem para a constituição de ideários docentes e, por vezes, orientam o trabalho dos professores em sala de aula.

Concluímos este texto com a consciência de que nossa investigação não engloba toda a complexidade envolvida nas discussões sobre possíveis contribuições, potencialidades e limitações dos instrumentos pedagógicos para a aprendizagem de conteúdos científico-escolares. Na verdade, ainda é necessário estudar e avançar na compreensão sobre o tema. É importante aprofundar a discussão desta temática, dada sua relevância para promover melhorias na qualidade dos processos educativos e contribuir para o desenvolvimento humano de alunos e professores.

Este estudo aponta para a necessidade da criação de espaços institucionais de discussões, durante os processos de formação inicial e continuada de professores, para oportunizar reflexões e entendimentos sobre a educação escolar, especialmente no que se refere à atividade social do professor e sua relação com o desenvolvimento humano. Consideramos fundamental que o professor tenha compreensões sobre como o sujeito/aluno aprende e se constitui, para, então, realizar sua atividade profissional, atentando para a escolha, utilização e diversificação de instrumentos de ensino e de avaliação. Os instrumentos pedagógicos podem viabilizar aprendizagens nos contextos educat ivos, bem como a const ituição dos sujeitos e a formação docente, à medida que são 
portadores de conhecimentos culturais produzidos, memorizados e referendados pela humanidade.

\section{Referências}

BONI, V.; QUARESMA, S. J. Aprendendo a entrevistar: como fazer entrevistas em Ciências Sociais. Revista Eletrônica dos Pós-Graduandos em Sociologia Política da UFSC, v. 2, n. 1, p. $68-80,2005$.

BRAGA, E. S. A constituição social da memória: uma perspect iva histórico-cultural. ljuí: Ed. Unijuí, 2000.

BRAGA, E. S. Tensões eu/outro: na memória, no sujeito, na escola. In: NOGUEIRA, L. H.; SMOLKA, A. L. B. Questões de desenvolvimento humano: prát icas e sent idos. Campinas, SP: Mercado de Letras, 2010.

CARVALHO, A. M.; GIL-PÉREZ, D. Formação de professores de Ciências: tendências e inovações. 10. ed. São Paulo: Cortez, 2011.

CONNE, F. Saber e conhecimento na perspect iva da transposição didática. In: BRUN, J. (org.). Didáctica das matemáticas. Lisboa: Inst ituto Piaget, 1996

ECCHELI, S. D. A mot ivação como prevenção da indisciplina. Educar, n. 32, p. 199-213, 2008.

GERALDI, C. M. G. Currículo em ação: buscando a compreensão do cotidiano da escola básica. Revista Pro-Posições, v. 5, n. 3, p. 111-132, nov. 1994.

GÜLLICH, R. I. C. Investigação-formação-ação em ciências: um caminho para reconstruir a relação entre livro didático, o professor e o ensino. Curitiba, PR: Prismas, 2013.

LAPLANE, A. L. F. Interação e silêncio na sala de aula. 1997. Tese (Doutorado em Educação) - Faculdade de Educação, Universidade Estadual de Campinas, Campinas, SP, 1997.

LEONTIEV, A. N. O desenvolvimento do psiquismo. São Paulo, SP: Centauro, 1978.

LÜDKE, M.; ANDRÉ, M. E. D. A. Pesquisa em educação: abordagens qualitativas. São Paulo: EPU, 1986.

LURIA, A. L. Curso de psicologia geral: atenção e memória. 2. ed. Rio de Janeiro: Civilização Brasileira, 1999. 3 V. 
MALDANER, O. A. Formação de professores para um contexto de referência conhecido. In: NERY, B. K.; MALDANER, O. A. (org.). Formação de professores: compreensões em novos programas e ações. Ijuí: Ed. Unijuí, 2014. p. 15-41.

MARTINS, L. M. O Desenvolvimento do Psiquismo e a Educação Escolar: contribuições à luz da psicologia histórico-cultural e da pedagogia histórico-crítica. Campinas, SP: Autores Associados, 2013.

MELO, É. S.; BASTOS, W. G. Avaliação escolar como processo de construção do conhecimento. Estudos em Avaliação Educacional, v. 23, n. 52, p. 180-203, maio/ago. 2012.

MORAES, R. Uma tempestade de luz: a compreensão possibilitada pela Análise Textual Discursiva. Ciência \& Educação, v. 9, n. 2, p. 191-211, 2003.

MORAES, R.; GALIAZZI, M. C. Análise textual discursiva. 2. ed. ljuí, RS: Unijuí, 2011.

MOURA, M. O. et al. Atividade orientadora de ensino: unidade entre ensino e aprendizagem. Revista Diálogo Educacional, v. 10, n. 29, p. 205-229, jan./abr. 2010.

MOURA, M. O.; SFORNI, M. S. F.; ARAÚJO, E. S. Objet ivação e apropriação de conhecimentos na at ividade orientadora de ensino. Revista Teoria e Prática da Educação, v. 14, n. 1, p. 39-50, jan./abr. 2011.

NEUVILLE, S. O valor das at ividades de aprendizagem: suas origens e seus efeitos. In: GALAND, B.; BOURGEOIS, É. Motivar-se para aprender. Campinas: Autores Associados, 2011. p. 81-93.

ROCHA, M. S. P. M. L. Práticas pedagógicas e a const ituição social da memória: proposições, tensões e contradições. In: SMOLKA, A. L. B.; NOGUEIRA, A. L. H. Estudos na perspectiva de Vigotski: gênese e emergência das funções psicológicas. Campinas, SP: Mercado de Letras, 2013.

SILVA, L. H. A. A perspect iva histórico-cultural do desenvolvimento humano: ideias para estudo e invest igação do desenvolvimento dos processos cognit ivos em Ciências. In: GÜLLICH, R. I. C. (Org.). Didática das ciências. Curit iba: Prismas, 2013.

SMOLKA, A. L. B. A memória em questão: uma perspectiva histórico-cultural. Educação \& Sociedade, n. 71, p. 166-193, jul. 2000a.

SMOLKA, A. L. B. O (im)próprio e o (im)pert inente na apropriação das prát icas sociais. Cadernos Cedes, ano xx, n. 50, p. 26-40, 2000 b.

SCHROEDER, E.; TOMIO, D. Atividades de estudo para aprend izagem e desenvolvimento de neoformações em aulas de Ciência: uma reflexão epistemológica a part ir da teoria histórico-cultural. ACTIO, Curitiba, v. 5, n. 1, p. 1-19, jan./abr. 2020. 
VIEIRA, V. A. M. A.; SFORNI, M. S. F. Avaliação da aprendizagem conceitual. Educar em Revista, n. especial 2, p. 45-58, 2010.

VIGOTSKI, L. S. A construção do pensamento e da linguagem. São Paulo, SP: Mart ins Fontes, 2001.

VIGOTSKI, L. S. A formação social da mente: o desenvolvimento dos processos psicológicos superiores. 7. ed. São Paulo: Mart ins Fontes, 2007.

VIGOTSKI, L. S.; LURIA, A. R. Estudos sobre a história do comportamento: símions, homem primitivo e criança. Porto Alegre: Artes Médicas, 1996.

WYZYKOWSKI, T. O trabalho educativo e sua relação com a constituição social da memória individual no processo de formação de professores. 2017. Dissertação

(Mestrado em Educação nas Ciências) - Universidade Regional do Noroeste do Estado do Rio Grande do Sul, Programa de Pós-Graduação em Educação nas Ciências, ljuí, RS, 2017.

YIN, R. K. Estudo de caso: planejamento e métodos. 2. ed. Porto Alegre: Bookman, 2001.

\footnotetext{
' Doutoranda em Educação nas Ciências pela Universidade Regional do Noroeste do Estado do Rio Grande do Sul (UNIJUÍ). Bolsista da Coordenação de Aperfeiçoamento de Pessoal de Nível Superior (CAPES). E-mail: tamini.wyzykowski@gmail.com

ii PhD pela Universidade Estadual Paulista Júlio de Mesquita Filho (UNESP) e doutora em Educação pela Universidade Federal do Rio Grande do Sul (UFRGS). Professora e pesquisadora do Programa de PósGraduação em Educação nas Ciências e do Departamento de Ciências da Vida da Universidade Regional do Noroeste do Estado do Rio Grande do Sul (UNIJUÍ). E-mail: marlif@unijui.edu.br
} 